\title{
Formulation development and in-vitro/ex-vivo evaluation of novel buccoadhesive films of metoprolol tartrate using $2^{3}$ factorial design techniques
}

\author{
T. Ayyappan ${ }^{1}$, D. Bharathiraja ${ }^{1 *}$ and T. Vetrichelvan ${ }^{2}$
}

${ }^{I}$ Department of Pharmaceutics

${ }^{2}$ Department of Pharma Analysis, Adhiparasakthi College of Pharmacy, Melmaruvathur, Tamilnadu, India-603319.

\begin{abstract}
The aim of present investigation was to develop an optimized buccoadhesive film of metoprolol tartrate, a BCS class I drug, to provide unidirectional sustained drug delivery to the buccal mucosa that has potential to enhance the bioavailability. The films were prepared using HPMC K4M as film former, carbopol $934 \mathrm{P}$ as buccoadhesive polymer and dimethyl sulfoxide as penetration enhancer, by solvent casting technique. The films were characterized for various pharmacotechnical parameters and $2^{3}$ full factorial design was employed to study the effect of independent variables. The design was validated by extra design checkpoint formulation (BF9). The response of design was employed to study the effect of independent variables. The responses of design were analyzed using Design Expert 8.0.7.1 and the analytical tools of software were used to draw pareto charts. On the basis of software analysis, formulation BF4 with desirability factor of 0.698 was selected as optimized formulation and was evaluated for independent parameters. Optimized formulation showed $12.05 \mathrm{hr}$, ex-vivo residence time, and good permeation (42.68\%) through goat buccal mucosa and $82.19 \%$ drug release after $8^{\text {th }}$ hour. The release kinetics of optimized formulation best fitted the higuchi model. Histopathological studies revealed no buccal mucosal damage. Hence BF4 formulation can be concluded as promising drug delivery system to enhance the permeability limited absorption of metoprolol tartrate.
\end{abstract}

Keywords: Metoprolol tartrate; $2^{3}$ full factorial design; Buccoadhesive film; Optimization; Pareto charts; Response surface plots; Histopathological studies

\section{Introduction}

The oral cavity is viewed as a convenient and easily accessible site for the delivery of therapeutic agents Ayyappan T and Kasture P.V (2005). Bandyopadhyay A. K (2008), and Gupta A et al., (1992). Within the oral cavity, drugs can be administered from the buccal gingiva or the sublingual space either for the treatment of local conditions (eg. thrush) or for the systemic treatment of diseases (eg. angina) Madhusudan RY et al., (2007). Naga RK et al., (2011), and (Nagendra KD et al., 2011). The advances in bioadhesive and controlled release technology have stimulated a renewal of interest in the delivery of drugs to, or via the buccal route Navneet G et al., (2010), Pankaj K, et al., (2012), and (Ramana M. V., et al., 2007). The buccal route of drug administration is the most widely used method for application of mucoadhesive delivery system. Both for the local treatment of inflammation and for rapid absorption of compounds, formulation technology have employed the buccal route for over two decades. The oral mucosa is covered by stratified squamous epithelium and three different types of mucosa can be distinguished: The masticatory, the lining and the specialized mucosa. Blood supply to the oral cavity tissues is delivered via the external carotid artery. The buccal mucosa lines the inner cheek and buccal formulations are placed in the mouth between the upper gingivae (gums) and cheek (sometimes referred as buccal pouch) to treat local and systemic conditions Ravi KRJ and Indira MY (2012), Venkatalashmi R et al., (2011).

Metoprolol tartrate is a cardio selective $\beta 1$ adrenergic antagonist and widely used in the treatment of hypertension, angina pectoris, cardiac arrhythmias and myocardial infarction. It is rapidly absorbed from oral route but undergoes first pass metabolism, which results in only $38 \%$ oral bioavailability. The half life of metoprolol tartrate is approximately 3-4 hours. Metoprolol tartrate was selected as model drug to avoid first pass hepatic metabolism and to improve the oral bioavailability and to control the release of the drug from the films by matrix forming polymers, as the half life of drug is low. In this investigation, buccoadhesive films of Metoprolol tartrate have been developed using anionic polymers like Carbopol 934P and non-ionic polymer Hydroxy propyl methyl cellulose K4M (HPMC K4M), each formulation had combination of anionic and non-ionic

*Corresponding author: 
polymers. The main objective of this work was to formulate and evaluate buccoadhesive Film of Metoprolol tartrate containing $50 \mathrm{mg}$ of drug, using a mucoadhesive polymer with the help of solvent casting method in order to the release for the period of 8 hours.

This type of formulation will ensure minimum fluctuations in the plasma drug concentration and reduced dosing frequency which in turn will result into improved patient compliance.

\section{Materials and methods}

\section{Materials}

Metoprolol tartrate was gifted sample for Madras pharmaceuticals Chennai. HPMC K4M,Carbopol 934P,DMSO were purchased by S.D. Fine Chem Ltd (Mumbai, India).All other chemicals and reagents were of analytical grade.

\section{Formulation design of $2^{3}$ full factorial design}

A $2^{3}$ randomized full factorial design was used in this study. Three factors were evaluated, each at two levels and experimental trials were performed on all eight possible combinations (Table I). The amount of HPMC K4M as film former (X1), and the amount of carbopol 934P as buccoadhesive polymer (X2) and concentration of DMSO as penetration enhancer (X3) were selected as independent variables. The percent cumulative drug release (\% CDR) at $8^{\text {th }}$ hour, ex-vivo residence time and cumulative $\%$ permeation at $8^{\text {th }}$ hour respectively were selected as dependent variables. Regression polynomials for the individual dependant variables were calculated with the help of Design Expert 8.0.7.1 software (Stat-Ease, Inc, USA) and applied to approximate the response surface and contour plots. The general model as shown below was generated-

\section{$\mathrm{Y}=\mathrm{B} 0+\mathrm{B} 1 \mathrm{X} 1+\mathrm{B} 2 \mathrm{X} 2+\mathrm{B} 3 \mathrm{X} 3+\ldots+\mathrm{B} 12 \mathrm{X} 1 \mathrm{X} 2+\mathrm{B} 13 \mathrm{X} 1 \mathrm{X} 3+\mathrm{B} 23 \mathrm{X} 2 \mathrm{X} 3+$ $\ldots .+\mathrm{B} 123 \mathrm{X} 1 \mathrm{X} 2 \mathrm{X} 3$}

$\mathrm{B} 1$ is estimated coefficient for the factor X1; similarly B2 and B3 are estimated coefficients for the factor X2 and X3 respectively. The main effects $(\mathrm{X} 1, \mathrm{X} 2$ and $\mathrm{X} 3$ ) represent the average result of changing one factor at a time from its low to high value. The interaction terms show how the response changes when three factors are simultaneously changed.

\section{Preparation of Buccoadhessive Film}

The buccoadhesive Film were prepared by solvent casting method. Each $2 \mathrm{~cm}$ film contained $50 \mathrm{mg}$ of Metoprolol tartrate.

\section{Backing layer}

For preparation of backing layer a glass petridish of $9.5 \mathrm{~cm}$ meterwas used as a casting surface. Backing membrane of ethyl cellulose was fabricated by slowly pouring a solution containing $500 \mathrm{mg}$ of ethyl cellulose and $2 \%$ dibutyl phthalate in $10 \mathrm{ml}$ of ethanol to the glass petridish and air drying for $1 \mathrm{hr}$.

Table I. $2^{3}$ Full Factorial design of Buccoadhesive films of metoprolol tartrate and the response parameters $(n=3)$

\begin{tabular}{|c|c|c|c|c|c|c|c|}
\hline $\begin{array}{l}\text { Formulation } \\
\text { code }\end{array}$ & Drug (mg) & $\begin{array}{c}\text { HPMC } \\
\text { K4M } \\
\% \text { w/v } \\
(\mathrm{X} 1)\end{array}$ & $\begin{array}{c}\text { Carbopol 934P } \\
\% \text { w/v } \\
\text { (X2) }\end{array}$ & $\begin{array}{c}\text { DMSO } \\
\% \mathrm{w} / \mathrm{v} \\
(\mathrm{X} 3)\end{array}$ & $\begin{array}{l}\% \text { CDR at } \\
8^{\text {th }} \text { hour }\end{array}$ & $\begin{array}{c}\text { Ex-Vivo } \\
\text { Residence } \\
\text { Time }\end{array}$ & $\begin{array}{c}\text { Cumulative \% } \\
\text { permeation } \\
\text { at } 8^{\text {th }} \text { hour }\end{array}$ \\
\hline $\mathrm{BF} 1$ & 50 & -1 & -1 & +1 & $92.19 \pm 0.60$ & $07.06 \pm 0.66$ & $39.60 \pm 1.50$ \\
\hline $\mathrm{BF} 2$ & 50 & -1 & -1 & -1 & $89.37 \pm 0.41$ & $10.41 \pm 0.07$ & $38.62 \pm 0.18$ \\
\hline BF3 & 50 & -1 & +1 & -1 & $80.26 \pm 0.67$ & $12.34 \pm 0.11$ & $40.07 \pm 0.06$ \\
\hline BF4 & 50 & -1 & +1 & +1 & $84.29 \pm 0.46$ & $12.81 \pm 0.57$ & $42.68 \pm 1.35$ \\
\hline BF5 & 50 & +1 & -1 & -1 & $77.54 \pm 0.51$ & $11.96 \pm 0.48$ & $36.64 \pm 0.18$ \\
\hline BF6 & 50 & +1 & -1 & -1 & $74.80 \pm 0.54$ & $11.68 \pm 0.54$ & $38.40 \pm 0.70$ \\
\hline BF7 & 50 & +1 & +1 & -1 & $73.56 \pm 0.42$ & $13.03 \pm 0.55$ & $41.21 \pm 0.12$ \\
\hline BF8 & 50 & +1 & +1 & +1 & $71.29 \pm 0.62$ & $13.05 \pm 0.03$ & $41.84 \pm 0.54$ \\
\hline BF9\# & 50 & 0 & 0 & 0 & $76.31 \pm 0.51$ & $10.68 \pm 0.51$ & $37.08 \pm 0.69$ \\
\hline
\end{tabular}

Actual values;X1, $+1=600 \mathrm{mg},-1=300 \mathrm{mg}, 0=450 \mathrm{mg} ; X 2 ;+1=100 \mathrm{mg},-1=50 \mathrm{mg}, 0=75 \mathrm{mg} ; X 3,+1=0.6 \mathrm{ml},-1=0.3 \mathrm{ml}, 0=0.45 \mathrm{ml} \quad \#$ extra design check point formulation 


\section{Buccoadhesive layer containing drug}

$3 \% \mathrm{w} / \mathrm{v}$ HPMC K4M was dissolved in $10 \mathrm{ml}$ of ethanol and water $(3: 2)$ under constant stirring till a clear solution was obtained. To this $1 \% \mathrm{w} / \mathrm{v}$ neutralized carbopol 934P $(0.5 \mathrm{~g}$ of carbopol 934P was neutralized by approximately $0.2 \mathrm{~g}$ of sodium hydroxide) and $5 \% \mathrm{v} / \mathrm{v}$ propylene glycol was added with stirring using magnetic stirrer. Then sufficient amount of metoprolol tratrate was added with stirring so as to have 50 $\mathrm{mg}$ of drug per $2 \mathrm{~cm}$ diameter of film. The mixture was stored at low temperature in order to remove air bubbles. The resultant clear solution was then poured on performed backing layer of ethyl cellulose and allowed to dry undisturbed for $4 \mathrm{~h}$ at $60{ }^{\circ} \mathrm{C}$ in the oven to ensure complete removal of solvent. The dried film was cut into discs of $2 \mathrm{~cm}$ diameter and packed in aluminium foil and stored in desiccators.

\section{Dimension (Diameter and Thickness) and folding endurance}

The thickness and diameter of the Film was determined using a Vernier caliper. Three Films from each type of formulation were used and average values were calculated.

Folding Endurance of the film was determined by repeatedly folding the films at the same place till it breaks. The films was folded in the center, between finger and thumb and then opened. This was one folding. The number of times, the film could be folded at the same place without breaking gave the value of folding endurance.

\section{Swelling studies by weight method}

The films were weighed individually (designated as Wo) and placed separately in $2 \%$ agar gel plates, incubated at $37+1{ }^{\circ} \mathrm{C}$ and examined for any physical changes. At regular $1 \mathrm{hr}$ time interval until 3 hours, films were removed from the gel plates and excess surface water was removed carefully using filter paper. The swollen films were then reweighed $\left(\mathrm{W}_{\mathrm{T}}\right)$ and the swelling index were calculated using the following formula:

$$
\% \mathrm{SW}=\left[\left(\mathrm{W}_{\mathrm{T}}-\mathrm{W}_{\mathrm{O}}\right) / \mathrm{W}_{\mathrm{O}}\right] \times 100
$$

\section{Surface $p H$}

The formulations were first wetted by adding $1 \mathrm{ml}$ distilled water to its surface. The surface $\mathrm{pH}$ was then recorded by bringing a glass electrode near the surface of the formulation and allowing it to equilibrate for $1 \mathrm{~min}$.

\section{Drug content}

Uniformity of drug content was determined by assaying the individual films. Three films from each batch were powdered individually and each was dissolved in $100 \mathrm{~mL}$ of isotonic phosphate buffer $\mathrm{pH} 6.8$ by stirring on a magnetic stirrer for 1 hours. The absorbance of each of these solutions was then measured on UV-visible spectrophotometer at $274.5 \mathrm{~nm}$.

\section{Ex-vivo bioadhesion study}

Measurement of adhesion force was determined with chemical balance method by using bovine buccal mucosa which was obtained from slaughter house. The underlying tissues were separated and washed thoroughly with phosphate buffer solution ( $\mathrm{pH}$ 6.8). The membrane was then tied to the bottom of the lower vial using rubber band. The vial was kept in glass bottle which was filled with phosphate buffer solution at $37 \pm 1{ }^{0} \mathrm{C}$ in such way that buffer just reaches the surface of mucosal membrane and kept it moist. The films to be tested was stuck on the lower side of the hanging Glass vial by using adhesive tape and the weight (2 $\mathrm{gm}$ ) on the right pan was removed. This lowered the left side of the pan along with the film over the mucosa. It was kept undisturbed for three minutes and the weights are added on right side of pan till the film just separated from the membrane surface. The excess weight on the right pan i.e. total weight minus 2 gm was taken as measure of bioadhesive strength. Bioadhesive force was calculated by using following equation.

$$
\text { Bioadhesive force }=\frac{\text { Bioadhesive Strength }}{100} \times 9.81
$$

\section{Ex-vivo residence time}

The ex-vivo Residence time was examined after application of the buccal film on freshly cut goat buccal mucosa. The fresh goat buccal mucosa was tied on the glass slide and a mucoadhesive core side of each film was wet with 1 drop of phosphate buffer ( $\mathrm{pH}$ 6.8) and pasted to the goat buccal mucosa by applying a light force with a fingertip for 50 seconds. The glass slide was then put in the beaker, which was filled with $200 \mathrm{ml}$ of the phosphate buffer and kept at $37^{\circ} \mathrm{C} \pm 1^{\circ} \mathrm{C}$. After 2 minutes, a slow stirring rate was applied to stimulate the buccal cavity environment and film adhesion was monitored for 14 hours. The time for the film to detach from the goat buccal mucosa was recorded as the Residence time.

\section{In- vitro drug release study}

The influence of technologically defined condition and difficulty in simulating in- vivo conditions has led to the development of a number of in-vitro release methods for buccal formulations, however, no standard method has yet been developed. In-vitro release rate of buccoadhesive Film of Metoprolol tartrate was carried out using rotating paddle apparatus (USP Type II). The dissolution medium consisted of $250 \mathrm{ml}$ of phosphate buffer (pH 6.8). The release study was performed at $37^{\circ} \mathrm{C} \pm 0.5^{\circ} \mathrm{C}$ with a rotation speed of $50 \mathrm{rpm}$. 
The sample $(5 \mathrm{ml})$ was withdrawn at time interval of 30 and 60 minutes up to $8 \mathrm{~h}$ and replaced with $5 \mathrm{ml}$ of dissolution media each time to maintain the sink conditions. The amount of Metoprolol tartrate released was determined spectrophotometrically at $274.5 \mathrm{~nm}$.

In-vitro buccal permeation The in-vitro buccal permeation study of metoprolol tartrate through goat buccal mucosa was performed using Franz diffusion cell. A specimen of fresh goat buccal mucosa was mounted between donar and receptor compartments. The film was placed on the mucosa, and the compartments were filled with $1 \mathrm{ml}$ of phosphate buffer $\mathrm{pH}$ 6.8. The receptor compartment was filled with isotonic phosphate buffer $\mathrm{pH} \quad 6.8$ maintained at $37.0 \pm 0.2^{\circ} \mathrm{C}$ and hydrodynamics in the receptor compartment were maintained by stirring magnetically at $50 \mathrm{rpm}$. Aliquots of $1 \mathrm{ml}$ sample were withdrawn at predetermined time intervals and analyzed UV spectrophotometer at $274.5 \mathrm{~nm}$.

\section{Histopathological studies}

Histopathological evaluation of goat buccal mucosa tissue (control)incubated in phosphate buffer saline solution $\mathrm{pH} 6.8$ was compared with that treated with buccal film for $8 \mathrm{hr}$. the tissue was properly washed twice using normal saline solution to remove the adhered tissues and protein. The tissue was fixed with $10 \%$ formalin, routinely processed and set in paraffin. Paraffin sections were cut on glass slides and stained with hematoxylin and eosin. Examine the transverse sections of treated goat buccal mucosa under light microscope to detect any cellular damage to buccal mucosa tissue.

\section{Statistical analysis of response by design expert software}

Design Expert 8.0.7.1 software was used for the analysis of effect of each variable on the designated response. Pareto charts were made for the analysis of each response coefficient for its statistical significance. Quantitative and qualitative contribution of each variable on each of the response was analyzed. The significant response polynomial equations generated by design expert were used to validate the statistical design. Response surface plots were generated to visualize the simultaneous effect of each variable on each response parameter. Possible interactions between $\mathrm{X} 1 \mathrm{X} 2$, $\mathrm{X} 2 \mathrm{X} 3$, and X1X3 were also studied and analyzed.

\section{Validation of experimental design}

The polynomial equations were utilized for validation of the experimental design. An extra check point formulation BF9 was prepared with the predicted value for of in-vitro drug release $\left(\% \mathrm{CDR}\right.$ at $\left.8^{\text {th }} \mathrm{hr}\right)$, Cumulative permeability at $8^{\text {th }} \mathrm{hr}$ and ex-vivo residence time. Experimental value were determined by formulating and evaluating BF9 and close resemblance between predicted and experimental value indicated validity of the generated model .Finally an optimized formulation was selected on the basis of higher in-vitro drug after $8 \mathrm{hr}(\% \mathrm{CDR})$,higher ex-vivo residence time , and higher cumulative \%permeability at $8 \% \mathrm{hr}$ with good desirability factor using software analysis.

\section{Results and discussion}

The buccoadhesive films of metoprolol tartrate were successfully prepared using HPMCK4M, carbopol 934P, propylene glycol and DMSO as per experimental design. Films consisting of a drug loaded buccoadhesive layer composed of HPMC K4M and carbopol 934P (hydrophilic); and a drug free non adhesive protective layer (hydrophobic); made up of ethyl cellulose.

\section{Pharmacotechnical characteristics of the films dimension (Thickness and diameter), weight of films and folding endurance}

The size (diameter) and thickness of the films of all formulations were reported. From each batch randomly three films were selected and weighed. The weight variations of films of all formulations were reported. Use of less amount of plasticizer was observed to cause brittleness in the medicated discs. The values were reported in the table II.

\section{In-vitro swelling study}

The films containing high level of carbopol 934P (BF3, BF4, BF7, BF8) exhibited higher degree of swelling as compared to films containing low level of carbopol 934P (BF1, BF2, $\mathrm{BF} 5, \mathrm{BF} 6)$. This is be due to the concentration based swelling behavior of carbopol 934P available for swelling, more will be the swelling index which is beneficial for buccoadhesion. Swelling phenomenon of the polymers makes strong secondary hydrogen bonding with buccal mucosa and thus results in mucoadhesion. Swelling results in the formation of thick swollen mass which provide unidirectional release of drug in sustained manner.

\section{Surface pH study}

These results indicated that there is no risk of mucosal damage or irritation while administering these formulations on buccal mucosal region.

\section{Content uniformity}

The content uniformity of the prepared buccoadhesive film of the metoprolol tartrate displayed more than $96 \%$ drug content. The drug content of prepared buccoadhesive films have within the range of 99.0 to $101.0 \%$ as specified in the official monographs. 
Table II. Pharmacotechnical evaluation of buccoadhesive films (BF1-BF8)

\begin{tabular}{|c|c|c|c|c|c|c|c|}
\hline $\begin{array}{c}\text { F. } \\
\text { Code }\end{array}$ & $\begin{array}{l}\text { Thickness } \\
(\mathrm{mm}) \pm \mathrm{SD}\end{array}$ & $\begin{array}{c}\text { Film } \\
\text { Weight } \\
\left(\mathrm{mg} / \mathrm{cm}^{2}\right) \\
\pm \mathrm{SD}\end{array}$ & $\begin{array}{c}\% \text { Drug } \\
\text { Content } \pm \\
\text { SD }\end{array}$ & $\begin{array}{c}\text { Surface } \\
\mathrm{pH} \\
\pm \mathrm{SD}\end{array}$ & $\begin{array}{c}\text { Swelling } \\
\text { Index } \\
(\%) \pm \mathrm{SD}\end{array}$ & $\begin{array}{l}\text { Folding } \\
\text { Endurance } \\
\quad \pm \mathrm{SD}\end{array}$ & $\begin{array}{c}\text { Ex-Vivo } \\
\text { Bucco } \\
\text { Adhesive } \\
\text { Strength }\end{array}$ \\
\hline \multirow{2}{*}{ BF1 } & 1.03 & 231.3 & 99.26 & 7.04 & 29.72 & 310.66 & 32.00 \\
\hline & \pm 0.017 & \pm 0.67 & \pm 1.03 & \pm 0.047 & \pm 0.660 & \pm 1.15 & \pm 1.000 \\
\hline \multirow{2}{*}{$\mathrm{BF} 2$} & 0.92 & 279.2 & 99.92 & 6.84 & 28.86 & 315.33 & 34.00 \\
\hline & \pm 0.060 & \pm 0.05 & \pm 0.49 & \pm 0.181 & \pm 0.890 & \pm 4.93 & \pm 1.000 \\
\hline \multirow{2}{*}{$\mathrm{BF} 3$} & 1.57 & 244.8 & 98.93 & 6.31 & 39.06 & 334.33 & 36.00 \\
\hline & \pm 0.479 & \pm 0.44 & \pm 0.85 & \pm 0.157 & \pm 0.690 & \pm 11.59 & \pm 1.000 \\
\hline \multirow{2}{*}{$\mathrm{BF} 4$} & 1.47 & 329.8 & 98.76 & 6.23 & 42.39 & 340.00 & 35.00 \\
\hline & \pm 0.110 & \pm 0.94 & \pm 0.28 & \pm 0.080 & \pm 0.400 & \pm 4.00 & \pm 1.000 \\
\hline \multirow{2}{*}{ BF5 } & 1.78 & 262.4 & 96.13 & 6.98 & 21.41 & 353.00 & 32.00 \\
\hline & \pm 0.064 & \pm 0.01 & \pm 1.24 & \pm 0.080 & \pm 0.370 & \pm 07.81 & \pm 1.520 \\
\hline \multirow{2}{*}{ BF6 } & 1.84 & 304.8 & 96.95 & 6.50 & 32.70 & 343.3 & 31.00 \\
\hline & \pm 0.094 & \pm 0.05 & \pm 1.78 & \pm 0.294 & \pm 0.670 & \pm 13.65 & \pm 1.000 \\
\hline \multirow{2}{*}{ BF7 } & 1.06 & 358.4 & 98.93 & 6.02 & 41.30 & 359.00 & 38.00 \\
\hline & \pm 0.015 & \pm 0.95 & \pm 0.49 & \pm 1.000 & \pm 0.130 & \pm 13.47 & \pm 2.000 \\
\hline \multirow{2}{*}{ BF8 } & 1.14 & 272.4 & 98.36 & 6.84 & 50.13 & 347.00 & 39.00 \\
\hline & \pm 0.191 & \pm 0.77 & \pm 1.59 & \pm 0.008 & \pm 0.420 & \pm 7.54 & \pm 3.200 \\
\hline \multirow{2}{*}{ BF9 * } & 1.92 & 258.5 & 97.97 & 6.04 & 45.00 & 350.6 & 31.00 \\
\hline & \pm 0.052 & \pm 0.04 & \pm 0.49 & \pm 0.294 & \pm 1.040 & \pm 10.26 & \pm 2.600 \\
\hline
\end{tabular}

\section{Ex-vivo bioadhesion study}

The results of ex-vivo buccoadhesive strength for metoprolol tartrate buccal films are shown in table 2. Thus BF1 was rejected and the rest of the formulations containing high level of carbopol $934 \mathrm{P}$ (BF3, BF4, BF7, and BF8) exhibited higher buccoadhesive strength than BF2, BF5, BF6 formulation which may be due to surface adhesion phenomenon as well as due to formation of secondary hydrogen bonds with mucosa as a result of rapid swelling of carbopol 934P. Buccoadhesion is also regulated by the addition of HPMC K4M. It has synergistic effect on buccoadhesiove strength over carbopol 934P, correspondingly BF7, BF8 displayed highest buccoadhesive strength.

\section{Assessment of response parameters}

\section{Ex-vivo residence time}

The ex-vivo Residence time was examined after application of the buckle films on freshly cut goat buckle mucosa. The result showed in Table revealed that the mean adhesion time was increased in the formulation batches containing Carpool 934P: HPMC K4M combination. This may be due to the flexibility of Carpool $934 \mathrm{P}$ chains, which easily diffuses and interpenetrates into the cumin and get entangled with that of cumin. The films containing high level of carpool 934P $(\mathrm{BF} 3, \mathrm{BF} 4, \mathrm{BF} 7, \mathrm{BF} 8)$ showed higher residence time of 11.34 to $12.05 \mathrm{hr}$ as films containing low level of carpool 934P 
(BF1, BF2, BF5, BF6) that show residence time of 7.06 to $10.68 \mathrm{hr}$. This may due to surface adhesion phenomenon as well as due to formation of secondary hydrogen bonds with goat buckle mucosa as a result of rapid swelling of carpool 934P. BF7 and BF8 show higher residence time than BF3 and BF4 due to presence of HPMC K4M at high level. Hence it can be concluded that ex-vivo residence time increased with increase in the HPMC concentration in the formulation.

\section{In-vitro drug release study}

Films containing low level of HPMC K4M (BF1,BF2,BF3,BF4)displayed higher in-vitro drug release $(92.19 \pm 0.60$ to $80.26 \pm 0.67)$ than formulations containing higher level of HPMC K4M (BF5,BF6,BF7,BF8)that displayed only $(71.29 \pm 0.62$ to $77.54 \pm 0.51)$ drug release after $8 \mathrm{hr}$ which may due to increase viscosity offered by the gelling of the hydrophilic HPMC K4M polymer. The increased viscosity of formulation resulted in a corresponding decrease viscosity of by the gelling of the hydrophilic HPMC K4M polymer. The increased viscosity of formulation resulted in a corresponding decrease in the release. A similar observation has been obtained by other reference drug. Whereas decrease in metoprolol tartrate release was obtained on increasing the concentration of HPMC and carbopol 934P. Though highest \%CDR of $92.19 \pm 0.60 \%$ at $8^{\text {th }}$ was recorded for BF 1 , the formulation was rejected based on poor ex-vivo residence time, thus BF4 was considered as second best formulation in terms of \%CDR (84.29\%)and least by BF8 (71.29\%) which is

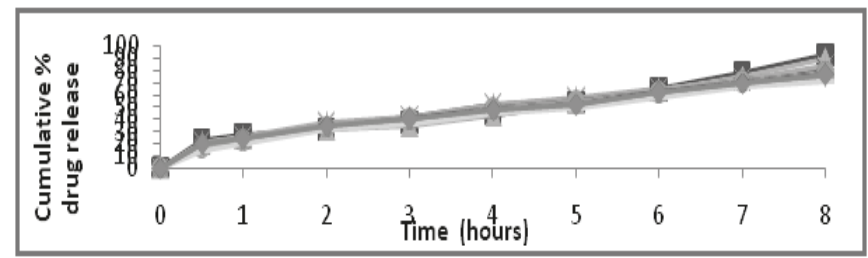

Fig. 2. Comparative Drug release profile of all Buccoadhesive Film.

showing an inverse relation between concentration of HPMC K4M and in-vitro drug release. In formulations $\mathrm{BF} 1, \mathrm{BF} 2, \mathrm{BF} 3, \mathrm{BF} 4$ drug release with increasing the concentration of carbopol $934 \mathrm{P}$. Since carbopol 934P is insoluble in stimulated saliva and swelling behavior of carbopol 934P is attributed to unchanged $\mathrm{COOH}$ group that get hydrated by forming hydrogen bonds on imbibing with water and therefore extending polymer chain. It was observed that films containing combination of high levels of both carbopo1934P and HPMCK4M exhibited delayed drug release indicating better matrix characteristics. Strong matrix integrity inhibits the entry of dissolution media and delays the dissolution of drug.

\section{In-vitro buccal permeation}

In-vitro drug permeation studies revealed that the release of Metoprolol tartrate from different formulations varies with the characteristics and composition of matrix forming polymers as shown in figure 3 .

In the experimental design, formulation BF2, BF4, BF6 and BF8 containing high level of DMSO showed higher permeation of metoprolol tartrate than formulations $\mathrm{BF} 1, \mathrm{BF} 3, \mathrm{BF} 5$ and BF7 which is Highlighting the significance of level of DMSO. Amongst all the films containing high levels of DMSO, the descending order for permeability coefficient was $\mathrm{BF} 8>\mathrm{BF} 4>\mathrm{BF} 6>\mathrm{BF} 2$ and it can be concluded that proper formulation optimization is essential.

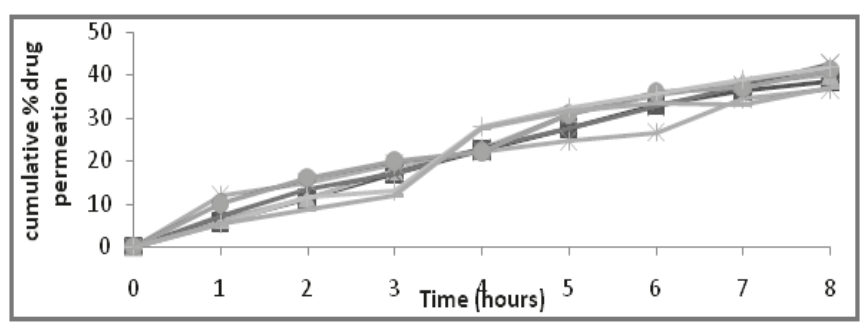

Fig. 3. Comparative Drug permeation profile of all Buccoadhesive Film Histopathological studies

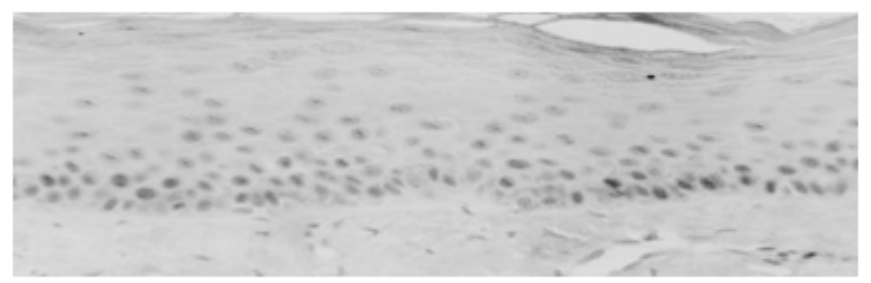

Fig. 4. Histopathological evaluation of transverse section of goat buccal mucosa treated with optimized formulation BF4

The goat buccal mucosa specimen at the end of permeation study of optimized formulation BF4 was subjected to histopathological evaluation. The microscopic observation of the transverse section showed no damage to the buccal mucosa at cellular level. All the layers mucus, stratum distendum, stratum basale, basal lamina and sub mucosa were found to be intact establishing the non-toxicity of the optimized film.

\section{Statistical analysis of response by design expert software}

Based on the results obtained for ex-vivo residence time, $\% \mathrm{CDR}$ at $8^{\text {th }} \mathrm{hr}$ and cumulative \%drug permeation at $8 \mathrm{th} \mathrm{hr}$, the response polynomial coefficients were determined in order to evaluate each response. Each response coefficient was studied for its statistical significance by Pareto charts as shown in figure. Pareto charts establish ' $t$ 'value of effect that is studied by two limit lines namely Bonferroni limit 
line ( $\mathrm{t}$ value of effect $=3.752$ ) and $\mathrm{t}$ limit line ( $\mathrm{t}$ value effect $=2.345$ ) coefficients with $t$ value of effect between Bonferroni line are designated as certainly significant coefficients with $t$ value of effect between Bonferroni line and $\mathrm{t}$ limit linear termed as coefficients likely to be significant, while $t$ value of effect below the $t$ limit line is statistically insignificant and should be removed from the analysis. The non-significant response coefficients were deleted and the following significant polynomial response equation(s) for ex-vivo residence time, \%CDR at $8^{\text {th }} \mathrm{hr}$ and cumulative $\%$ drug permeation at $8^{\text {th }} \mathrm{hr}$ were generated.

$$
\begin{aligned}
& \text { Ex-vivo residence time }= 11.17+0.86 \mathrm{X}_{1}+\left(0.524 \times\left[\mathrm{X}_{2}\right]\right)+\left[0.495 \times\left(\mathrm{X}_{3}\right)\right]+ \\
& {\left[0.187 \times\left(\mathrm{X}_{1} \mathrm{X}_{2} \mathrm{X}_{3}\right)\right] \ldots \ldots \ldots \ldots . . \mathrm{eq} 3 } \\
& \% \mathrm{CDR} \text { at } 8^{\text {th }} \mathrm{hr} \quad 80.41-6.85 \mathrm{X}_{1}+\left[-0.964 \times\left(\mathrm{X}_{2}\right)\right]+\left[-0.959 \times\left(\mathrm{X}_{3}\right)\right]+ \\
& {\left[-0.362 \times\left(\mathrm{X}_{1} \mathrm{X}_{2} \mathrm{X}_{3}\right)\right] \ldots \ldots \ldots \ldots \text {.eq } 4 } \\
& \text { Cumulative \%drug }= 38.63+258 \mathrm{X} 1+[0.663 \times(\mathrm{X} 2)]+[0.634 \times(\mathrm{x} 3)]+ \\
& \text { Permeated at } 8^{\text {th }} \mathrm{hr} \quad\left[0.240 \times\left(\mathrm{X}_{1} \mathrm{X}_{2} \mathrm{X}_{3}\right)\right] \ldots \ldots \text {.eq } 5
\end{aligned}
$$

\section{Validation of experimental design}

These equations were utilized for validation of the equation of the experimental design. An extra design checkpoint formulation (BF9) was prepared and the predicted values for ex-vivo residence time, $\% \mathrm{CDR}$ at $8^{\text {th }} \mathrm{hr}$ and cumulative $\%$ permeation at $8^{\text {th }} \mathrm{hr}$ were generated. Experimental values were determined by formulating and evaluating BF9, and close resemblance between predicted and experimental values indicated validity of generated model.

Interactions studies and response surface plots:

The possible interactions between X1X2, X2, X3and X1X3 for each response were also investigated. The response surface plots generated using polynomial equations represent quantitative simultaneous effect of any two variables at constant level. The results were similar to interaction studies but were quantifiable. However Design Expert software can analyze both qualitative and quantitative effects of variables on the response parameters and hence can facilitative selection of nntimized formulation.

s.
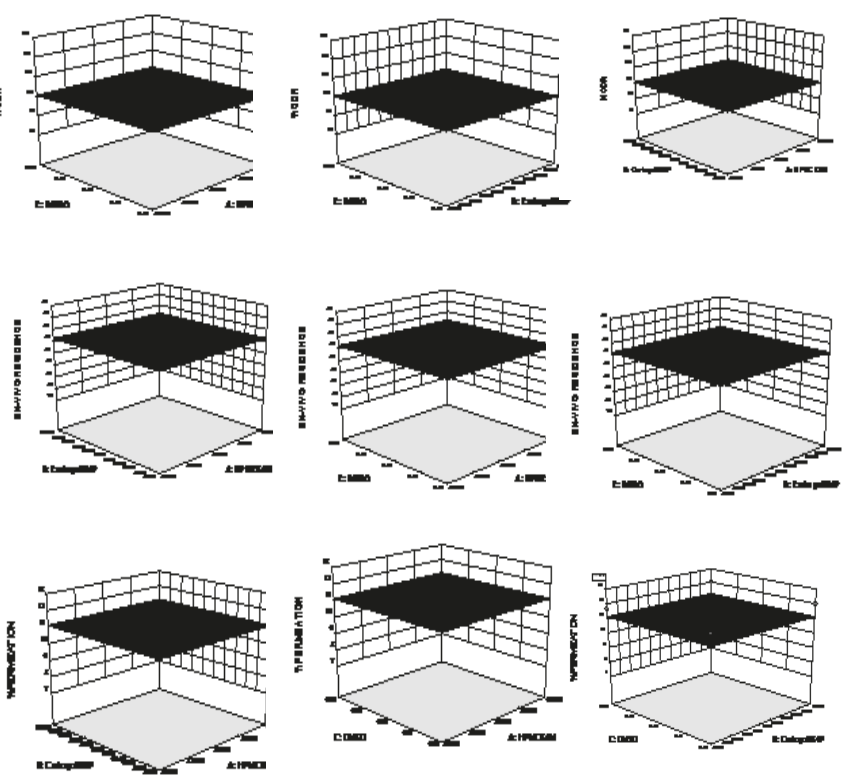

Table IV. Evaluation of extra design check point formulation BF9 and optimized formulation BF4

\begin{tabular}{lcccc}
\hline Response parameter & Formulation code & Predicted value & Experimental value & \%RSD \\
\hline \%CDR at $8^{\text {th }} \mathrm{hr}$ & BF9 & 76.39 & $76.31 \pm 0.51$ & 0.08 \\
& BF4 & 80.41 & $34.29 \pm 0.49$ & 3.88 \\
Cumulative \% permeation & BF9 & 36.55 & $37.05 \pm 0.69$ & 0.5 \\
at $8^{\text {th }} \mathrm{hr}$ & BF4 & 38.63 & $42.68 \pm 1.35$ & \\
& & & & \\
Ex-vivo residence & BF9 & $10.68 \pm 0.51$ & 0.15 \\
time (hr) & BF4 & 11.17 & $11.81 \pm 0.57$ & 0.74 \\
\hline
\end{tabular}
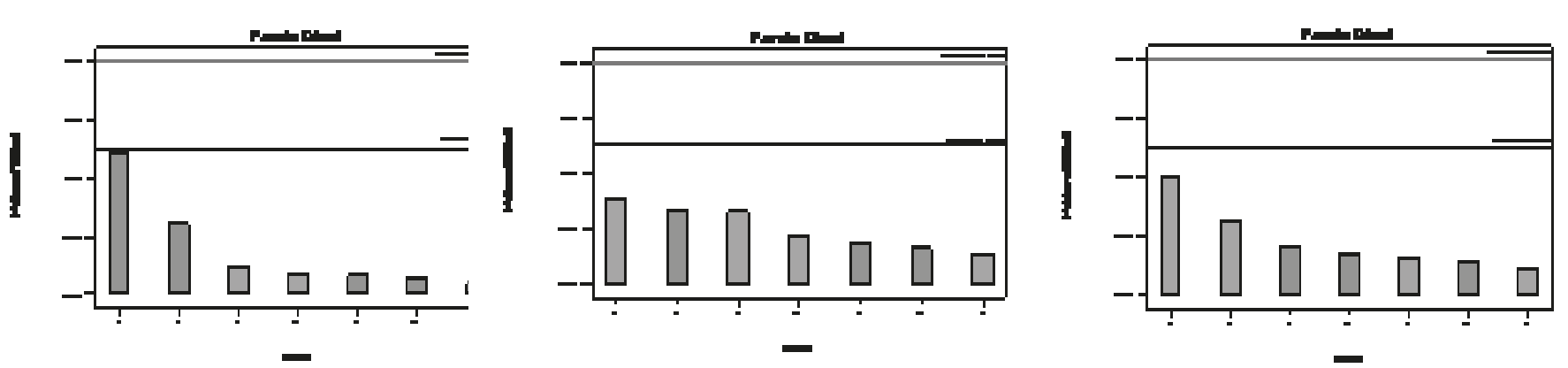

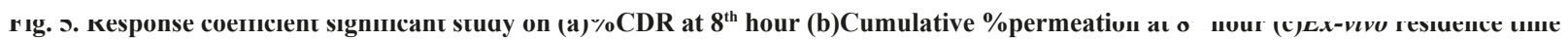




\section{Selection of optimized formulation}

The qualitative and quantitative influence of independent variables on ex-vivo residence time, \%permeability and $\%$ CDR were clearly interpreted from by design Expert that is an equally advantageous tool for selection of optimized formulation. The tools offer the possibility to vary each variable simultaneously and present optimum selections with their respective desirability value. According to our criteria of higher $\% \mathrm{CDR}$ at 8 th hour, higher residence time and higher cumulative \%drug permeated after 8 hour, BF4 was selected as optimized formulation. Consequently, the coded optimized level for the amount of HPMC K4M, concentration of Carbopol 934P and volume of DMSO for BF4 were identified as $-1,+1$, and +1 respectively.

\section{Acknowledgement}

The authors are very much thankful to his holiness Arulthiru Bangaru Adigalar, President, with respect to Thirumathi V. Lakshmi Bangaru Adigalar, Vice President for providing entire facilities for the research work. Authors are also thankful to all those who helped us in direct or indirect way to carry out this study successfully.

\section{References}

Ayyappan T and Kasture P.V (2005), Development and in vitro evaluation of a buccoadhesive Ondansetron Hydrochloride tablet formulation, Indian Drugs. 43(2): 92-95.

Bandyopadhyay A. K (2008), Novel drug delivery systems. 1st edn., Everest publishing house, Pune, 143: pp. 194-197.

Gupta A, Garg S, and Khar R.K (1992), Measurement of bioadhesive strength of mucoadhesive buccal Film: design of an in vitro assembly, Indian Drugs. 50: $152-155$.

Madhusudan RY, Vamshi VY, Chandrasekhar K, and Ramesh G (2007), Development of Mucoadhesive Patches for Buccal Administration of Carvedilol, Current Drug Delivery. 4: 27-39.
NagaRaju K, Velmurugan S, Deepila B, Sundar vinu shitha (2011), Formulation and in-vitro evaluation of buccal tablets of Metoprolol tartrate, Int J Pharm Pharmaceut Sci. 3(2): 239-246.

Nagendra Kumar D, Shirsand Para MS, and Makadia K (2011), Design and Evaluation of metoprolol tartrate containing Buccal tablets, Dhaka Uni J Pharm Sci. 10(2): 101-108.

Navneet G, Arya1 RK., Akanksha G. and Neetesh NJ (2010), Development and evaluation of mucoadhesive buccal Film of Salbutamol Sulphate, Int J Pharm Pharmaceut Sci. 2(2): 40-43.

Pankaj Kumar, Gulshan Chabra,and Kamla Pathak (2012), Development and Statistical Optimization of Buccoadhsive films of Amiloride Hydrochloride; in-vitro and ex-vivo Evaluation, Ind J Pharm Edu Res, 2(46): 145-153.

Ramana M. V., Nagda C. and Himaja M (2007), Design and evaluation of mucoadhesive buccal drug delivery systems containing Metoprolol Tartarate. Indian $J$ Pharm Sci. 69(4): 515-518.

Ravikumar Reddy J, Indira muzib Y (2012), Formulation and Evaluation of mucoadhesive Buccal film of Amiloride Hydrochloride. Int J Green Tech and Pharm Sci. 3(3): 828-837.

Venkatalashmi R, Yajaman Sudhakar, Madhuchudana Chetty C, and Mohan Varma M (2011), Buccal drug Delivery from metoprolol tartrate polymeric mucoadhesive film, J of Pharm Res. 4(11): 3892-3896.

Received: 20 October 2013; Revised: 24 February 2014; Accepted: 03 June 2014. 